\title{
Article \\ Modified Activated Carbon for Copper Ion Removal from Aqueous Solution
}

\author{
Wei-Sheng Chen $(\mathbb{1}$, Yun-Chung Chen * and Cheng-Han Lee *(i)
}

check for updates

Citation: Chen, W.-S.; Chen, Y.-C.; Lee, C.-H. Modified Activated Carbon for Copper Ion Removal from Aqueous Solution. Processes 2022, 10, 150. https://doi.org/10.3390/ pr10010150

Academic Editors: Juu-En Chang and Yi-Kuo Chang

Received: 27 December 2021

Accepted: 10 January 2022

Published: 12 January 2022

Publisher's Note: MDPI stays neutral with regard to jurisdictional claims in published maps and institutional affiliations.

Copyright: (C) 2022 by the authors. Licensee MDPI, Basel, Switzerland. This article is an open access article distributed under the terms and conditions of the Creative Commons Attribution (CC BY) license (https:// creativecommons.org/licenses/by/ $4.0 /)$.

\author{
Department of Resources Engineering, National Cheng Kung University, No. 1, Daxue Rd., East Dist., \\ Tainan City 701401, Taiwan; kenchen@mail.ncku.edu.tw \\ * Correspondence: n46091130@gs.ncku.edu.tw (Y.-C.C.); n48091013@gs.ncku.edu.tw (C.-H.L.)
}

\begin{abstract}
Because of increasing environmental awareness, it is becoming more important to remove harmful elements from water solutions. This study used activated carbon (AC) derived from waste wood-based panels as the base material, oxidized with nitric acid (OAC), and grafted with iminodiacetic acid (IDA-OAC) to improve the adsorption capacity and affinity for metals. The characterization of AC, OAC, and IDA-OAC was conducted via FTIR, SEM, $\mathrm{N}_{2}$ adsorption and desorption analysis, elemental analysis, Boehm titration, and point of zero charge (PZC). The instrument studies proved the modified increasing of the functional groups of the adsorbents. Moreover, batch and column experiments were conducted to evaluate the ability of the three adsorbents to remove copper ions from aqueous solution. In batch sorption, IDA-OAC had the highest adsorption capacity $(84.51 \mathrm{mg} / \mathrm{g})$ compared to OAC $(54.74 \mathrm{mg} / \mathrm{g})$ and $\mathrm{AC}(24.86 \mathrm{mg} / \mathrm{g})$ at $\mathrm{pH}$. The breakthrough point $\left(C_{t} / C_{i}=0.05\right)$ of copper ions for IDA-OAC occurred much later than AC in the column experiment $(\mathrm{AC}=19 \mathrm{BV}$, IDA-OAC $=52 \mathrm{BV})$. The Langmuir isotherm and pseudo-second-model kinetics modeling could better fit with the data obtained from the batch sorption of AC, OAC, and IDA-OAC. The significant capacity and reusability of IDA-OAC displayed high applicability for water treatment.
\end{abstract}

Keywords: adsorption; waste recycling; iminodiacetic acid; surface modification; copper ion

\section{Introduction}

US EPA has reported that metal water pollution is a severe worldwide problem due to the rapid development of industry and technology [1]. Some specific metal compounds are toxic, nonbiodegradable, persistent, bioaccumulated, and cause cancer, so treating metal pollutants in aqueous solutions is a significant issue [2,3]. Among many metals, copper is commonly found in industrial wastewater [4]. It has been widely used in semiconductors, electronic product manufacturing, and electroplating. Copper poisoning can cause nausea, diarrhea, liver, and kidney failure due to long-term exposure to copper through contaminated food and water sources [5]. For these reasons, many techniques have been developed to effectively remove metals from wastewater to meet the discharge standard of water pollutants, such as ion exchange [6], electrochemical treatment [7], chemical precipitation [8], reverse osmosis [9], and adsorption [5,10,11].

In these methods, adsorption by activated carbon (AC) is considered as a prospective approach to eliminate copper from wastewater, because of its easy implementation, high efficiency, low initial cost, and reusability $[5,12]$. It has widely been used in the removal of various contaminants from wastewater due to its high porosity parameter, great surface area, surface functional groups, and insensitivity to toxic environments [13-15]. On account of its many advantages, there have been many biowastes used for the fabrication of activated carbon materials, such as sawdust [16], paulownia wood [17], rice straw [18], and waste wood-based panels [19]. These biowastes also contain lignin and celluloses as commercial activated carbon precursors that can be a considered choice and low-cost sources to produce activated carbon [3]. 
In addition, with effluent standards becoming stricter in order to control pollution impacts, the modification of carbon materials has attracted extensive attention in recent years. The adsorption capacity of carbon materials is significantly relative to their pore structure and surface chemistry [13]. The surface modifications of a material can enhance the adsorption capacity and removal efficiency by increasing the active functional groups with a high affinity for metals on an adsorbent surface [20]. For example, $\mathrm{HNO}_{3}$ oxidized biochar showed remarkably higher adsorption performance than the unmodified carbon via introducing functional groups [10]. Zuo et al. functionalized biochar with hydrogen peroxide, which caused several oxygen-containing groups on the material surface, enhancing the affinity for copper [14]. Among the many surface modifiers, fixing iminodiacetic acid (IDA) chelating functional group into materials and its use as an adsorbent can be helpful for wastewater restoration [15]. Katarzyna et al. modified graphene oxide with IDA for effectivity preconcentration and removal of $\mathrm{Cu}(\mathrm{II})$ from water samples $(108.4 \mathrm{mg} / \mathrm{g})$ [21]. Razak et al. grafted kenaf fiber with IDA and increased the adsorption capacity by about $200 \%$ for $\mathrm{Cu}$ (II) removal [22]. Both oxygen and nitrogen on IDA can provide electron pairs to form coordination with transition metals. This endows the adsorbent with the ability to effectively attract copper to remove metals from the water [23].

Therefore, activated carbon derived from waste wood-based panels has been oxidized with $\mathrm{HNO}_{3}$ to enhance the number of oxygen-containing functional groups on the carbon material in this study. Afterwards, we grafted IDA to enhance the adsorption ability, affinity, and removal efficiency. A batch experiment was conducted to examine the influence of the solution $\mathrm{pH}$, reaction time, initial concentration, and temperature on adsorption. The data from the batch sorption were verified with equilibrium and kinetic adsorption models to identify the adsorption mechanisms from the adsorption procedure. The revitalization experiment was carried out to make the adsorbent more economical. Lastly, the column system was also used to study AC, OAC, and IDA-OAC.

\section{Materials and Methods}

\subsection{Chemicals and Materials}

The $\mathrm{H}_{3} \mathrm{PO}_{4}(\geq 85.0 \%)$, nitric acid $(\geq 65.0 \%)$, hydrochloric acid $(\geq 37 \%)$, iminodiacetic acid (IDA) ( $\geq 98 \%$ ), epichlorohydrin (EPI) ( $>99 \%), \mathrm{NaHCO}_{3}(\geq 99.7 \%), \mathrm{Na}_{2} \mathrm{CO}_{3}(\geq 99.8 \%$ ), $\mathrm{NaOH}(\geq 98 \%), \mathrm{NaCl}(99.9 \%), \mathrm{NaNO}_{3}(>99 \%)$, and $\mathrm{Cu}\left(\mathrm{NO}_{3}\right)_{2} \cdot 3 \mathrm{H}_{2} \mathrm{O}(99 \%)$ were purchased from Uni-Onward Corp. Chemicals used in this research were all of analytical quality. $\mathrm{N}_{2}$ (99.5\%) was purchased from Yun Shan Gas Co. Waste wood-based panels (WWP) were collected from the local recycling center. They were cut into small pieces $(1 \sim 4 \mathrm{~mm})$ and then washed several times with DI water. They were then dried in the oven at $333 \mathrm{~K}$ for $24 \mathrm{~h}$ and stored in a scintillation vial for subsequent usage.

\subsection{Preparation of Adsorbents}

\subsubsection{Fabrication of Activated Carbon from WWP}

Activated carbon was fabricated via chemical activation. Specifically, WWP was impregnated with $\mathrm{H}_{3} \mathrm{PO}_{4}(85.0 \% \mathrm{w} / \mathrm{w})$ at $298 \mathrm{~K}$ and placed in an oven at $383 \mathrm{~K}$ for $24 \mathrm{~h}$. The impregnation ratio was 3:1 $\left(\mathrm{H}_{3} \mathrm{PO}_{4} / \mathrm{WWP}\right.$ mass ratio). After that, a weighed amount of the dried mixture was put in the porcelain boat placed into a furnace, and heated up to $823 \mathrm{~K}$ for $2 \mathrm{~h}$ under continuous $\mathrm{N}_{2}$ flow $(150 \mathrm{~mL} / \mathrm{min} \mathrm{STP})$ at a constant heating rate $(10 \mathrm{~K} / \mathrm{min})$. The activated carbon was cooled to room temperature and washed with distilled water until constant $\mathrm{pH}$. This resulting sample was dried at $333 \mathrm{~K}$ for $24 \mathrm{~h}$ and sieved to a uniform size fraction of $0.595 \mathrm{~mm}-0.149 \mathrm{~mm}$.

\subsubsection{Activated Carbon Oxidation}

To increase the bond with the metal and the subsequent grafting site, we oxidized the activated carbon to increase oxygen-containing groups (such as hydroxyl, carboxyl) on the surface with $\mathrm{HNO}_{3}$. For this, the $1 \mathrm{~g}$ of dried AC was impregnated in $10 \mathrm{~mL}$ of $7 \mathrm{~N}$ nitric acid solution for three hours at $353 \mathrm{~K}$. After treatment, the residual material was filtered 
with filter paper and washed with distilled water until constant $\mathrm{pH}$, and dried at $333 \mathrm{~K}$ for constant weight.

\subsubsection{Synthesis of IDA-OAC}

For fixing iminodiacetic acid on OAC, epichlorohydrin was reacted with primary hydroxyl on the OAC through electrophilic substitution. Afterward, nucleophilic substitution occurred between the amino groups on IDA and the epoxy rings on the OAC. Specifically, $1.0 \mathrm{~g}$ of oxidized activated carbon (OAC) was dispersed in aliquots of ethanol $(20 \mathrm{~mL}), 1 \mathrm{M}$ of $\mathrm{NaOH}(10 \mathrm{~mL})$, and epichlorohydrin $(10 \mathrm{~mL})$. The mixture was agitated for $3 \mathrm{~h}$ at $313 \mathrm{~K}$. After that, it was cooled to room temperature and collected by filtration, and washed with DI water dried at $333 \mathrm{~K}$ for $24 \mathrm{~h}$, and abbreviated as EPI-OAC. Next, EPI-OAC (1.0 g), IDA $(4.0 \mathrm{~g}), 100 \mathrm{~mL}$ of distilled water were mixed and stirred at $333 \mathrm{~K}$ for $10 \mathrm{~h}$. The system was controlled to maintain the $\mathrm{pH}$ of the mixture higher than 10 during the reaction by adding $\mathrm{NaOH}$ solution. Finally, it was dried at $333 \mathrm{~K}$ for $24 \mathrm{~h}$ after the mixture solution was collected, and washed with diluted acetic acid and water, and abbreviated as IDA-OAC.

\subsection{Characterization}

The concentrations of $\mathrm{Cu}(\mathrm{II})$ ions were measured by ICP-OES (Varian, Palo Alto, CA, USA, Vista-MPX). The characteristics of the AC, OAC and IDA-OAC adsorbents were determined as follows: FTIR spectra for assessing the functional group's presence were recorded within a range from 4000 to $500 \mathrm{~cm}^{-1}$ using potassium bromide pallet in a Perkin Elmer, Spectrum one spectrometer. The changes of element content of $\mathrm{C}, \mathrm{N}, \mathrm{H}$, and $\mathrm{S}$ were analyzed by an elemental analyzer (Unicube, Elementar Analysensysteme $\mathrm{GmbH}$, Hanau, Germany). The surface morphology was determined with the Scanning Electron Microscopy (SEM) (EFE-SEM; SU-5000, HITACHI, Chiyoda ku, Japan). The BET surface area (Brunauer-Emmett-Teller) and pore structure were analyzed by adsorption and desorption with nitrogen at $77 \mathrm{~K}$ (Micromeritics ASAP 2020 specific surface analyzer). Before the gas adsorption measurement, the samples were degassed at $105^{\circ} \mathrm{C}$ for $8 \mathrm{~h}$. The Boehm titration method was performed to determine the acidic surface functional groups on the materials [24]. The $\mathrm{pH}$ drift method was used to determine the adsorbent's $\mathrm{pH}$ point of zero charges $\left(\mathrm{pH}_{\mathrm{PZC}}\right)$ [25].

\subsection{Batch Sorption of Copper}

In the batch adsorption process, $\mathrm{Cu}\left(\mathrm{NO}_{3}\right)_{2} \cdot 3 \mathrm{H}_{2} \mathrm{O}$ were used to prepare $\mathrm{Cu}$ (II) ions. A series of sorption was studied by adding $0.02 \mathrm{~g}$ of AC, OAC, IDA-OAC into $20 \mathrm{~mL}$ of a specific concentration of $\mathrm{Cu}$ (II) solution and agitated at a rate of $110 \mathrm{rpm}$ in a shaker incubator. The temperature and the time factors were adjusted in the experiment. The influence of $\mathrm{pH}$ on adsorption experiments was processed at $298 \mathrm{~K}$, and the $\mathrm{HNO}_{3}$ or $\mathrm{NaOH}(0.01-1.0 \mathrm{M})$ solutions were used to adjust the $\mathrm{pH}$ value from 2 to 6 . The effect of cations on the removal of $\mathrm{Cu}$ (II) was determined by adding 1000 to $5000 \mathrm{mg} / \mathrm{L} \mathrm{NaNO}_{3}$ with a $\mathrm{Cu}$ (II) concentration of $300 \mathrm{mg} / \mathrm{L}$, and the mixture was shaken for $24 \mathrm{~h}$ at $298 \mathrm{~K}$. For the determination of the impact of the different initial concentrations $(5,10,30,50,80$, $100,150$, and $200 \mathrm{mg} / \mathrm{L})$, the solution was agitated for $24 \mathrm{~h}$ at a suitable $\mathrm{pH}$ value $(\mathrm{pH}=5)$. The factor of contact time $(4,8,16,32,60,120,180,240$, and $300 \mathrm{~min})$ was determined at $298 \mathrm{~K}$ at optimum $\mathrm{pH}$ with a $\mathrm{Cu}$ (II) concentration of $200 \mathrm{mg} / \mathrm{L}$. Further, the influence of temperature (298, 308 and $318 \mathrm{~K}$ ) was analyzed. After each adsorption process, the filtrate was collected and analyzed by ICP-OES to measure the $\mathrm{Cu}$ (II) concentration. The adsorption capacity $\left(q_{e}, \mathrm{mg} / \mathrm{g}\right)$ of the copper and removal efficiency $(\mathrm{R} \%)$ were calculated using the following equation [11]:

$$
\begin{gathered}
q_{e}=\frac{\left(C_{0}-C_{e}\right) V}{W} \\
\mathrm{R}(\%)=\frac{\left(C_{0}-C_{e}\right)}{c_{0}}
\end{gathered}
$$


where $C_{0}$ is the initial concentration and $C_{e}$ is the equilibrium concentration of the copper solution $(\mathrm{mg} / \mathrm{L})$, and $V(\mathrm{~L})$ and $W(\mathrm{~g})$ are the volume of the $\mathrm{Cu}(\mathrm{II})$ solution and the weight of the adsorbent usage, respectively.

\subsection{Equilibrium Isotherms, Adsorption Kinetics, and Thermodynamic Studies}

To better understand the adsorption reactions with the primary mechanism and to investigate how copper ions interacted with adsorbents, the adsorption results with different initial concentrations were fitted with Langmuir isotherm (Equation (3)) and Freundlich isotherm (Equation (4)) models [15,26].

$$
\begin{gathered}
\frac{C_{e}}{q_{e}}=\frac{C_{\mathrm{e}}}{q_{\max }}+\frac{1}{K_{L} q_{\max }} \\
\ln (q e)=\ln K_{F}+\frac{1}{n} \ln C_{e}
\end{gathered}
$$

where $q_{\max }(\mathrm{mg} / \mathrm{g})$ signifies the maximum adsorption capacity. $q_{e}(\mathrm{mg} / \mathrm{g})$ is the concentration of $\mathrm{Cu}(\mathrm{II})$ solution under equilibrium. $K_{L}$ is a Langmuir constant related to the adsorption energy $(\mathrm{L} / \mathrm{mg}) . C_{e}(\mathrm{mg} / \mathrm{L})$ is the concentration of $\mathrm{Cu}(\mathrm{II})$ solution in equilibrium. $K_{F}(\mathrm{mg} / \mathrm{g})$ represents the Freundlich constants relative adsorption capacity of the adsorbent, and $1 / n$ is the Freundlich coefficient about heterogeneity.

Adsorption kinetics of $\mathrm{Cu}$ (II) on adsorbent used experimental data about the effect of contact time to fit separately by pseudo-first (Equation (5))- and second (Equation (6))-order kinetic models [27].

$$
\begin{gathered}
\ln \left(q_{e}-q_{t}\right)=\ln q_{e}-k_{f} t \\
\frac{t}{q_{t}}=\frac{t}{q_{e}}+\frac{1}{k_{s} q_{e}^{2}}
\end{gathered}
$$

where $q_{t}(\mathrm{mg} / \mathrm{g})$ is the quantities of $\mathrm{Cu}(\mathrm{II})$ adsorbed at the time, and $q_{e}(\mathrm{mg} / \mathrm{g})$ is the adsorbed amounts of $\mathrm{Cu}$ (II) under equilibrium, while $k_{f}(1 / \mathrm{min})$ and $k_{s}(\mathrm{~g} /(\mathrm{mg} \cdot \mathrm{min}))$ are the corresponding rate constants of pseudo-first- and second-order kinetic models, respectively.

The data from the effect of temperature on the adsorption process were used for determining three thermodynamic parameters: change in free energy $\left(\Delta \mathrm{G}^{\circ}\right)$, change in the enthalpy $\left(\Delta \mathrm{H}^{\circ}\right)$ and entropy variation $\left(\Delta \mathrm{S}^{\circ}\right)$. These parameters were calculated from the van't Hoff equation [28]:

$$
\begin{gathered}
\Delta \mathrm{G}^{\circ}=-R T \ln K_{d} \\
\ln K_{d}=\frac{\Delta \mathrm{S}^{\circ}}{R}-\frac{\Delta \mathrm{H}^{0}}{R T} \\
K_{d}=\frac{C_{0}-C_{e}}{C_{0}} \times \frac{V}{M}
\end{gathered}
$$

where $R(8.314 \mathrm{~J} /(\mathrm{mol} \mathrm{K}))$ is the universal gas constant, $K_{d}(\mathrm{~L} / \mathrm{mol})$ is the adsorption coefficient, $T$ is the absolute temperature in Kelvin. Using the slope and intercept of the plot of $\ln K_{d}$ versus $1 / T$, one can obtain the value of the $\Delta \mathrm{S}^{\circ}$ and $\Delta \mathrm{H}^{\circ}$.

\subsection{Reusability of IDA-OAC}

To make the IDA-OAC adsorbent more economical and practical, regeneration and reusability experiments were carried out. In the regeneration experiment, the adsorbent which loaded copper ion was eluted (solid/liquid ratio of $1 \mathrm{~g} / \mathrm{L}$ at $298 \mathrm{~K}$ for $24 \mathrm{~h}$ ) with $0.1 \mathrm{M} \mathrm{HCl}$, $0.1 \mathrm{M} \mathrm{HNO}_{3}$, and $0.1 \mathrm{M} \mathrm{H}_{2} \mathrm{SO}_{4}$, respectively. After regeneration, the adsorbent was collected, washed, and dried for the subsequent three adsorption/desorption experiments.

\subsection{Column Sorption of Copper}

The column-scale experiments were evaluated in continuous adsorption. About $0.2 \mathrm{~g}$ of the AC, OAC and IDA-OAC was wet-packed in a plexiglass column which was $4 \mathrm{~mL}$ in 
volume and $11.2 \mathrm{~mm}$ in diameter. The effect of initial $\mathrm{Cu}(\mathrm{II})$ concentration $(50 \mathrm{mg} / \mathrm{L})$ was analyzed. Before feeding the influents into the column, a peristaltic pump was pumped downward through the column with distilled water for about $3 \mathrm{~h}$. The flow rate for fixed-bed experiments was $1 \mathrm{~mL} / \mathrm{min}$ at $\mathrm{pH} 5$ (optimum value from batch-scale studies) and $12 \mathrm{BV} / \mathrm{h}$. The samples were collected from the exit with a fraction collector until a saturation state occurred. The following equations were used for data analysis of fixed-bed adsorption [29].

$$
\begin{gathered}
q_{t o t}=\frac{Q_{V} \mathrm{~A}}{1000}=\frac{Q_{V}}{1000} \int_{t=0}^{t=t_{t o t}}\left(C_{i}-C_{t}\right) d t \\
m_{t o t}=\frac{C_{i} Q_{V} t_{t o t}}{1000} \\
\mathrm{R} \%=\frac{q_{t o t}}{m_{t o t}} \times 100
\end{gathered}
$$

where $q_{t o t}$ is the total mass of the adsorbent in the column, $Q_{v}$ has been determined as the flow rate $(\mathrm{mL} / \mathrm{min}), C_{i}(\mathrm{mg} / \mathrm{L})$ and $C_{t}(\mathrm{mg} / \mathrm{L})$ are the inlet and outlet of $\mathrm{Cu}(\mathrm{II})$ concentration, the $m_{\text {tot }}(\mathrm{mg})$ and $\mathrm{R} \%$ present the total quantity of adsorbate flow through the column and the removal rate, respectively. The area under the breakthrough curve is marked as $\mathrm{A}$ and the plots of $C_{t} / C_{i}$ against bed volume are called the breakthrough curves. $C_{t} / C_{i}=0.05$ and 0.95 are signed as the breakthrough points $\left(p_{b}\right)$ and exhaustion points $\left(p_{e}\right)$, respectively.

\section{Results and Discussion}

\subsection{Characterization of Adsorbents}

The FT-IR spectra of possible functional groups on adsorbents are presented in Figure 1. For AC, because these carbons were activated by phosphoric acid, the peaks at $1156 \mathrm{~cm}^{-1}$ and $1060 \mathrm{~cm}^{-1}$ could be assigned to bending vibrations in $\mathrm{C}-\mathrm{OH}$ bonds and vibration of the polyphosphate chain, respectively [30]. The peak around $1617 \mathrm{~cm}^{-1}$ could be attributed to $\mathrm{C}=\mathrm{C}$ stretching vibration from the aromatic ring and conjugated $\mathrm{C}=\mathrm{O}$ bond [31]. Furthermore, the board band between 3250 to $3700 \mathrm{~cm}^{-1}$ represent the overlapped stretching and vibration from amine groups(-NH) and hydroxyl groups(-OH) [32]. This observation was found in OAC and IDA-OAC also. After the nitric acid treatment, the peak was observed at $1700 \mathrm{~cm}^{-1}$ due to the $\mathrm{C}=\mathrm{O}$ stretches of carboxyl or carbonyl groups [33], and the C-O stretching at $1216 \mathrm{~cm}^{-1}$ [34] proved that oxidation generates more oxygenated functional groups on the activated carbon. With the iminodiacetic acid grafted, the absorption bands at $1224 \mathrm{~cm}^{-1}$ and $1060 \mathrm{~cm}^{-1}$ related to C-O epoxyl and alkoxyl groups on EPI-OAC disappeared [21]. Then, the characterization of peaks related to bending vibration of $\mathrm{N}-\mathrm{H}$ or stretching vibration of $-\mathrm{C}=\mathrm{O}$ was shown at $1615 \mathrm{~cm}^{-1}[30,32]$. The peaks at $1384 \mathrm{~cm}^{-1}$ and $1140 \mathrm{~cm}^{-1}$ corresponded to C-N stretching [35], indicating the IDA was successfully grafted on OAC [36].

Elemental analysis was used to observe the change in contents of the AC, OAC, and IDA-OAC. From Table 1, after the nitric acid treatment and iminodiacetic acid was grafted, the nitrogen content of OAC and IDA-OAC increased from $1.490 \%$ to $2.080 \%$, and $1.490 \%$ to $2.410 \%$ compared to AC, respectively. The nitrogen on the AC was from the adhesives of the waste wood-based panels [19]. Moreover, the content of carbon decreased when the $\mathrm{N} \%$ increase. This change indicates that nitric acid and iminodiacetic acid successfully introduce the functional groups on the surface of activated carbon [37]. 


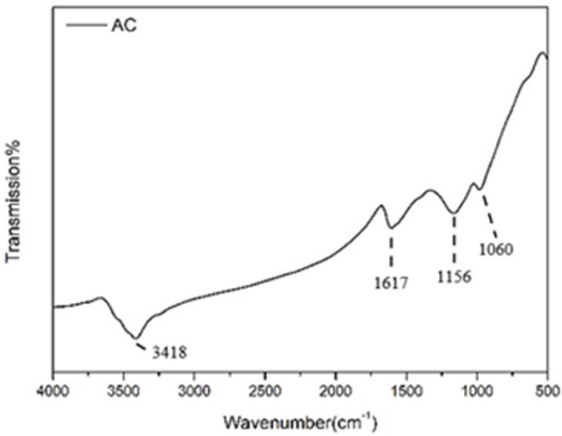

(a) $\mathrm{AC}$

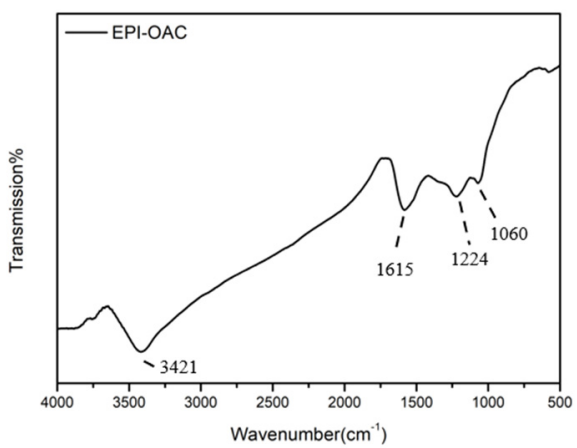

(c) EPI-OAC

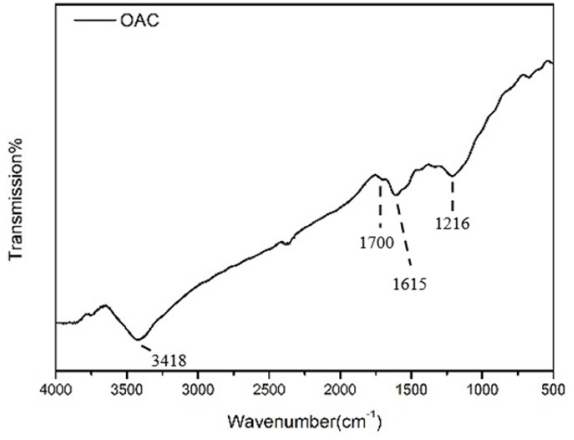

(b) OAC

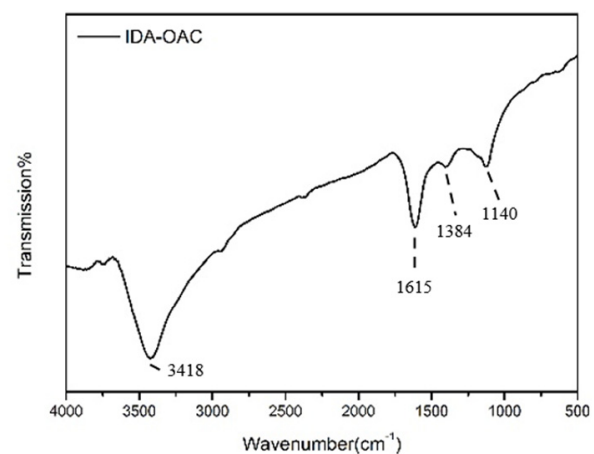

(d) IDA-OAC

Figure 1. FT-IR spectrum of AC, OAC, EPI-OAC and IDA-OAC.

Table 1. Element analysis of AC, OAC, and IDA-OAC.

\begin{tabular}{cccc}
\hline Sample & AC & OAC & IDA-OAC \\
\hline $\mathrm{C}(\mathrm{wt} \%)$ & 63.911 & 55.104 & 52.803 \\
$\mathrm{~N}(\mathrm{wt} \%)$ & 1.490 & 2.080 & 2.410 \\
$\mathrm{H}(\mathrm{wt} \%)$ & 2.251 & 2.986 & 2.397 \\
$\mathrm{~S}(\mathrm{wt} \%)$ & N.D. & N.D. & N.D. \\
\hline
\end{tabular}

N.D. $<0.01 \%$.

The surface morphology information was obtained through the SEM technique. The SEM images (Figure 2) of AC, OAC, and IDA-OAC reveal the difference between the materials before modifying and after. As illustrated in Figure $2 \mathrm{a}$, the activated carbon fabrication from waste wood-based panels had some open pores on the surface. In Figure 2b, homogenous porosity was observed when the magnification was enlarged [24]. After treating with the nitric acid, Figure $2 c-f$ displayed the open pores obviously and exhibited a heterogeneous surface with porosity. This could be attributed to nitric acid destroying the pore wall and causing the pore structure to collapse [38]. In addition, although Figure 2c,e was not much different, Figure 2d,f demonstrated that in OAC after grafting with iminodiacetic acid, the surface of the adsorbent became coarser and fluffier. This phenomenon confirms that the functional ligand bonding with the OAC surface provides more active sites to the adsorbate [39]. 


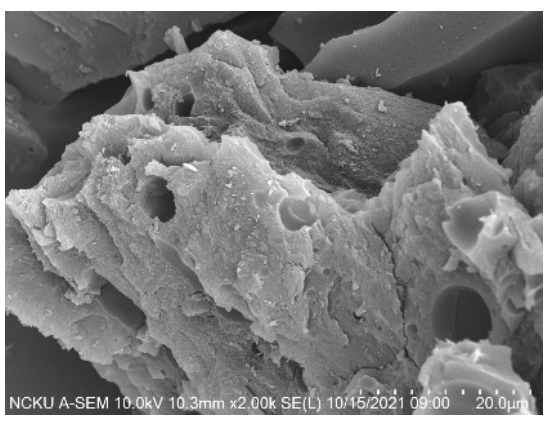

(a) AC

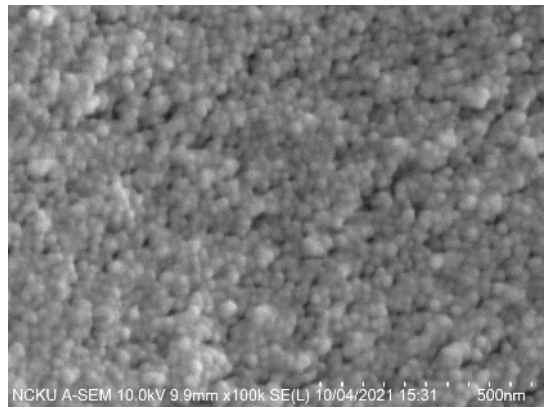

(b) AC

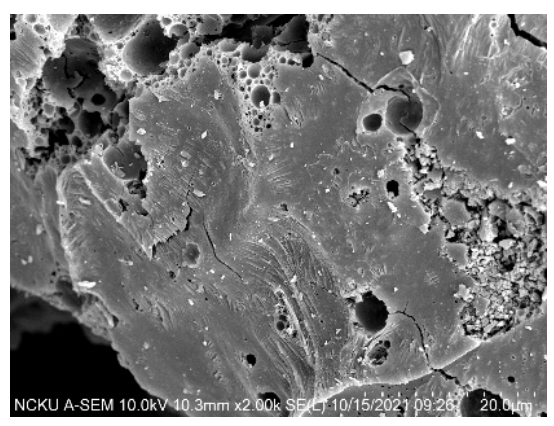

(c) OAC

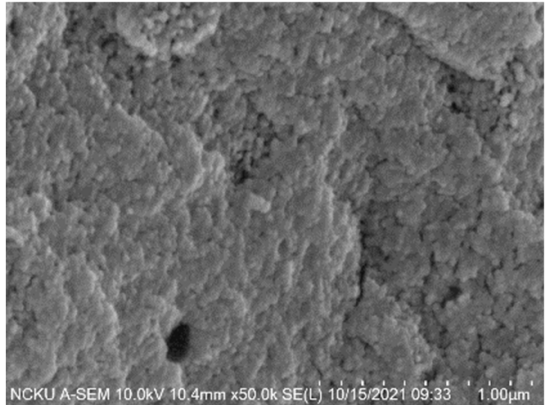

(d) OAC

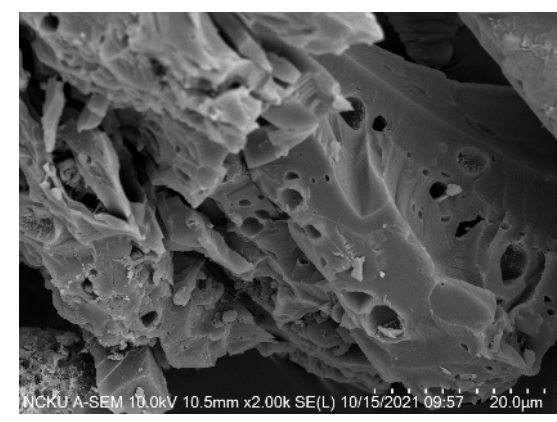

(e) IDA-OAC

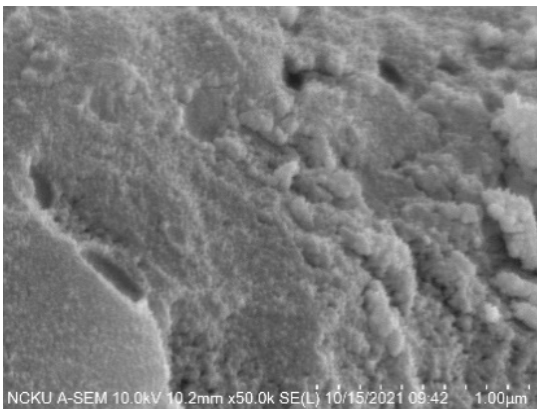

(f) IDA-OAC

Figure 2. SEM images of $(\mathbf{a}, \mathbf{b})$ AC, $(\mathbf{c}, \mathbf{d})$ OAC, $(\mathbf{e}, \mathbf{f})$ IDA-OAC.

To understand more surface physicochemical characteristics, the surface area, pore capacity, pore width, and contents of surface functional groups of adsorbents are shown in Table 2. Initially, the AC exhibited much higher pore properties. After nitric acid oxidation and grafting, the surface area, pore volume, and pore width were lower in the AC. This situation was due to the introduction of the functional groups inside the pores of activated carbon, and the lower stability of the aliphatic being oxidized, causing the destruction of the porous structure $[28,40]$. Although there was a decrease in the pore width, the average size was still contained in the mesopore $(2-50 \mathrm{~nm})$. The adsorbate having a larger radius could be due to the pores also [41]. The number of surface acidic functional groups was determined through the Boehm titration. The results displayed an increment of total acidic groups after modifying AC and iminodiacetic acid grafting on OAC (increase from 2.25 to $3.72 \mathrm{mmol} / \mathrm{g}$ and 3.72 to $3.93 \mathrm{mmol} / \mathrm{g}$, respectively). This proved that the nitric acid and iminodiacetic acid effectively introduced the functional group on AC through oxidization and grafting [42].

Table 2. Physicochemical parameters of AC, OAC, and IDA-OAC.

\begin{tabular}{cccc}
\hline Sample & AC & OAC & IDA-OAC \\
\hline Surface area $\left(\mathrm{m}^{2} / \mathrm{g}\right)$ & 1464.0757 & 996.0884 & 611.2244 \\
Pore volume $\left(\mathrm{cm}^{3} / \mathrm{g}\right)$ & 1.1731 & 0.5488 & 0.3082 \\
Pore width $(\mathrm{nm})$ & 3.2051 & 2.2039 & 2.0167 \\
Total acidity groups $(\mathrm{mmol} / \mathrm{g})$ & 2.25 & 3.72 & 3.93 \\
Carboxyl $(\mathrm{mmol} / \mathrm{g})$ & 1.05 & 2.03 & 2.22 \\
Lactone $(\mathrm{mmol} / \mathrm{g})$ & 0.74 & 1.02 & 0.86 \\
Phenolic $(\mathrm{mmol} / \mathrm{g})$ & 0.46 & 0.67 & 0.85 \\
$\mathrm{pH}_{\mathrm{pzc}}$ & 3.21 & 2.68 & 4.94 \\
\hline
\end{tabular}




\subsection{Effect of $\mathrm{pH}$ Value}

Because the different solution $\mathrm{pH}$ strongly affects the form of the surface charge on the adsorbent and the state of the copper for adsorption capacity, the $\mathrm{pH}$ value is a significant factor for the adsorption process [15]. As seen in Figure 3, the phenomenon can be observed that more copper adsorption on the three kinds of adsorbent follows the increasing $\mathrm{pH}$ value (2 to 6). Junior et al. used chelating resin with the iminodiacetic acid group to recover $\mathrm{Cu}^{2+}$, and found that the adsorption of the metal increases with the higher $\mathrm{pH}$, although the adsorbent was more selective for metals at low $\mathrm{pH}$ value [23]. The lowest adsorption quantity was found at $\mathrm{pH} 2$ due to more hydrogen ions being competitive with copper ions for the active sites in the solution [5]. At pH 6, more $\mathrm{OH}^{-}$ions might exist in the solution, causing hydrolysis or the precipitation of copper, affecting the adsorbent capacity [27,42]. Thus, the optimum $\mathrm{pH}$ was 5 for this study. In addition, through the measurement of point of zero charges, the surface charge of adsorbents is shown in Table 1 . The surface of the adsorbent was more positively charged when the $\mathrm{pH}$ is $<\mathrm{pH}_{\mathrm{pzc}}$; this could cause electrostatic repulsion between the adsorbent and the metal. On the contrary, if the solution $\mathrm{pH}>\mathrm{pH}_{\mathrm{pzc}}$, the functional group on the adsorbent is negatively charged because of the deprotonation [21]. This phenomenon enhances the affinity to copper ions. The AC, OAC, and IDA-OAC of $\mathrm{pH}_{\mathrm{pzc}}$ indicated that adsorbents present a weakly acidic characteristic; they efficiently operate at higher $\mathrm{pH}$ values. Xie et al. presented the same result in which the adsorption capacity for copper became higher when $\mathrm{pH}$ was increased by using the acidic adsorbent [42]. For the above reasons, a solution of $\mathrm{pH} 5$ was used in the following experiments.

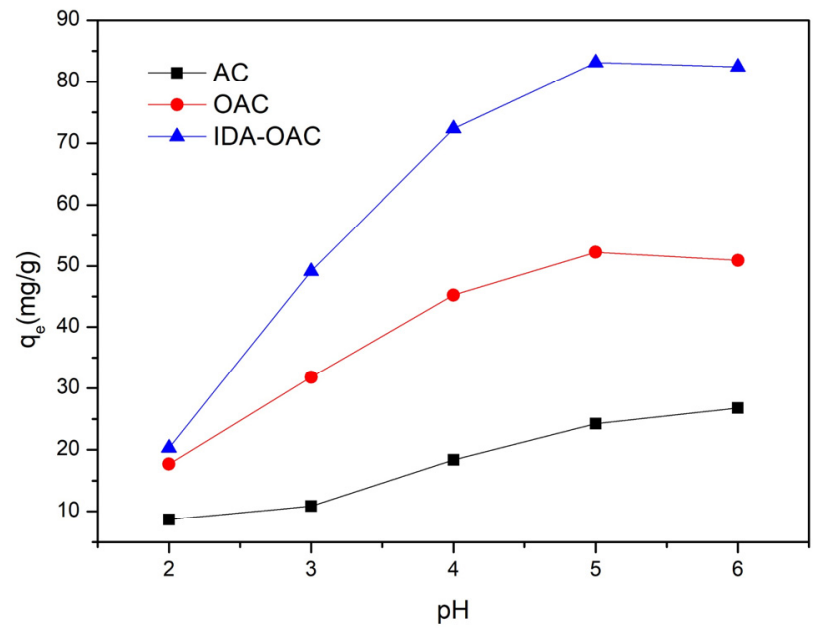

Figure 3. The impact of $\mathrm{pH}$ on the copper ion removal of AC, OAC, and IDA-OAC.

\subsection{Effect of Ion Strength}

The ionic strength study is significant for the adsorbents in practical operations. Therefore, we investigated the effect of $\mathrm{AC}, \mathrm{OAC}$, and IDA-OAC on adsorption with various concentrations of $\mathrm{NaNO}_{3}(1000 \sim 5000 \mathrm{mg} / \mathrm{L})$. As shown in Figure 4, the adsorption capacity decreased with the increase in ionic strength. This could be attributed to competition between $\mathrm{Na}^{+}$and $\mathrm{Cu}^{2+}$ for the adsorption sites [26]. In addition, the IDA-OAC exhibited a relatively stable adsorption capacity in high ion strength. It could also adsorb $69.7 \mathrm{mg}$ copper ions per gram in the environment containing $5000 \mathrm{mg} \mathrm{Na}^{+}$. This demonstrates that the iminodiacetic acid prefers to combine with $\mathrm{Cu}^{2+}$ than $\mathrm{Na}^{+}$and that providing a ligand for inner-sphere surface complexation reduces the influence of the variation of ionic strength $[23,28]$. Li et al. used an adsorbent with a dithiocarbamate functional group to uptake lead in high concentrations of sodium, which maintained high adsorption capacity because the sulfur atoms could provide ligands for the metals [28]. 


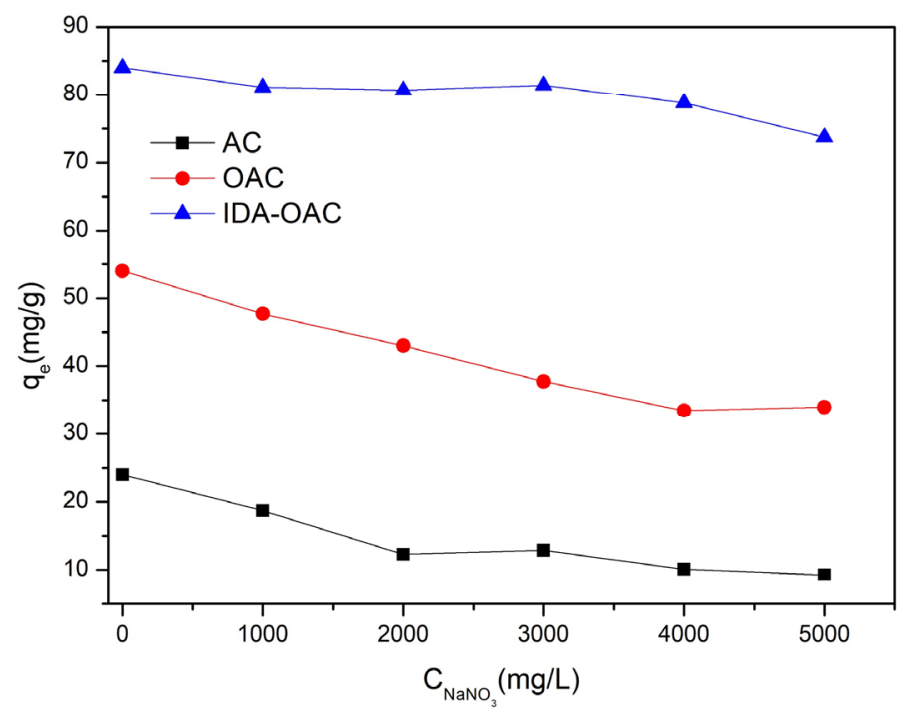

Figure 4. Effect of ion strength on the copper ion removal AC, OAC, and IDA-OAC.

\subsection{Effect of Initial Concentration and Equilibrium Isotherms}

The effect of variation in the initial concentration of $\mathrm{Cu}(\mathrm{II})$ on $\mathrm{AC}, \mathrm{OAC}$, and IDAOAC uptake amount and removal rate is presented in Figure 5. When the solutions reached equilibrium, it was revelated that the adsorption capacities rose with metal ion concentration (5 to 200 (mg/L)). The main reason is that more $\mathrm{Cu}(\mathrm{II})$ in the aqueous solution causes a higher driving force to overcome the mass transfer resistance for the adsorbent to uptake adsorbate [20]. At optimum conditions, IDA-OAC revealed the highest adsorption capacity $(84.51 \mathrm{mg} / \mathrm{g}$ ) compared to OAC (54.74 mg/g) and AC (24.86 mg/g). Compared to modifying the silicon dioxide with ethylenediaminetetraacetic acid $(\mathrm{Cu} 23.9 \mathrm{mg} / \mathrm{g})$, this result proved that the AC through the oxidized and grafted IDA could efficiently enhance the adsorption ability [43]. In addition, although the removal rate of an adsorbent relies on the initial concentration, the OAC and IDA-OAC perform a high removal rate for copper ions at low concentrations, especially IDA-OAC. IDA-OAC removed about $100 \%$ of Cu(II) for the concentration at $50 \mathrm{ppm}$. The tridentate ligand on the IDA exhibited a high affinity to metal ions [21]. This could ensure that the adsorbate has been completely removed from the aqueous solution.

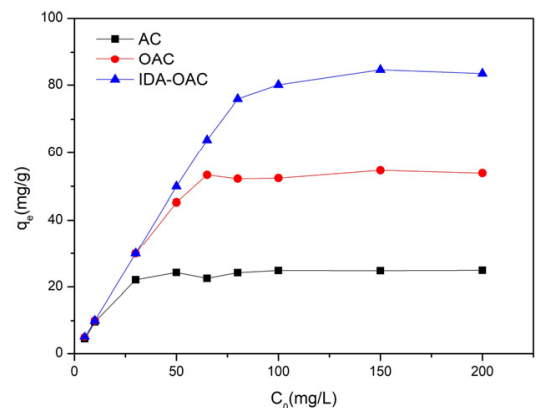

(a)

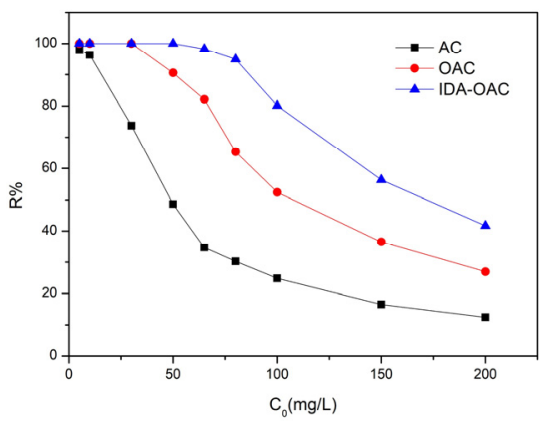

(b)

Figure 5. The adsorption capacity (a) and the removal efficiency (b) for AC, OAC, and IDA-OAC in the different initial concentrations.

The Langmuir and Freundlich isotherm models have usually simulated the adsorption result with a different initial concentration at a constant temperature [26]. This is useful in order to know how the adsorbates interact with adsorbents. The two isotherm model plots of AC, OAC, and IDA-OAC are illustrated in Figure 6. The adsorption parameter 
is presented in Table 3. The results showed that the Langmuir isotherm was more fitted than the Freundlich model according to the regression coefficient $\left(R^{2}\right)$. For all the three adsorbents, the correlation coefficient of the Langmuir model was more significant than 0.99. This indicated that the copper ions tended to adsorb onto adsorbents homogeneously through monolayer adsorption [5]. Waly et al. used the AC and OAC to adsorb metals derived from water hyacinth and found the same results [39]. Xie et al. also observed that the copper interacted with activated carbon and oxidized carbon, which was well explained by the Langmuir adsorption model [42]. Moreover, the mechanism for the transition metals adsorption on grafted IDA material was also reported by Fu et al. [27]. The copper ion commonly occurs in the monolayer with adsorption by a chelating functional group [44]. The experimental data were almost close together, with the $q_{m}(\mathrm{mg} / \mathrm{g})$ values calculated from the Langmuir model being $25.04 \mathrm{mg} / \mathrm{g}(\mathrm{AC}), 53.99 \mathrm{mg} / \mathrm{g}$ (OAC), and $83.75 \mathrm{mg} / \mathrm{g}$ (IDA-OAC), respectively. Moreover, the $K_{L}$ value for IDA-OAC was higher than other adsorbents, demonstrating that the higher binding energy is favorable to copper [45]. Table 4 is shown the different adsorbents maximum adsorption capacity for copper.

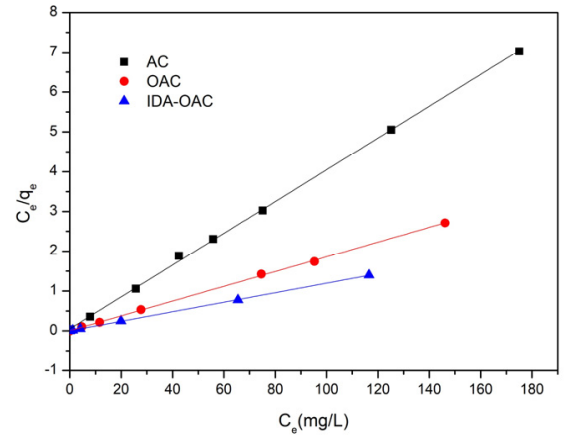

(a)

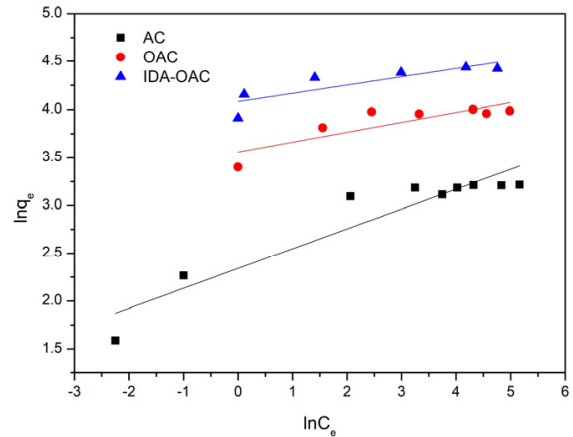

(b)

Figure 6. (a) Langmuir isotherm and (b) Freundlich isotherm model plots of AC, OAC, and IDA-OAC adsorption for $\mathrm{Cu}(\mathrm{II})$.

Table 3. The fitting results of Langmuir and Freundlich isotherm models.

\begin{tabular}{cccccccc}
\hline Sample & $\boldsymbol{q e}(\mathbf{m g} / \mathbf{g})$ & \multicolumn{3}{c}{ Langmuir Isotherm } & \multicolumn{3}{c}{ Freundlich Isotherm } \\
\hline & & $\boldsymbol{q}_{\boldsymbol{m}}(\mathbf{m g} / \mathbf{g})$ & $\boldsymbol{K}_{\boldsymbol{L}}$ & $\boldsymbol{R}^{\mathbf{2}}$ & $\mathbf{1 / n}$ & $\boldsymbol{K}_{\boldsymbol{F}}$ & $\boldsymbol{R}^{\mathbf{2}}$ \\
\hline AC & 24.86 & 25.04 & 0.74 & 0.9993 & 0.21 & 10.38 & 0.8745 \\
OAC & 54.74 & 53.99 & 2.69 & 0.9996 & 0.10 & 35.21 & 0.6742 \\
IDA-OAC & 84.51 & 83.75 & 5.74 & 0.9998 & 0.09 & 59.27 & 0.6667 \\
\hline
\end{tabular}

Table 4. Comparison of studies on copper ion removal.

\begin{tabular}{cccc}
\hline Adsorbent & $\mathrm{pH}$ & Capacity $\left(q_{\max }(\mathbf{m g} / \mathbf{g})\right)$ & Ref \\
\hline PN-Fe3O4-IDA & $\mathrm{pH}=5$ & 47.66 & {$[26]$} \\
PVDF-g-G3 PAMAM membrane & $\mathrm{pH}=5$ & 153.8 & {$[46]$} \\
$\mathrm{Fe}_{3} \mathrm{O}_{4} @ \mathrm{SiO}_{2}$-EDTA & $\mathrm{pH}=5.3$ & 36.86 & {$[43]$} \\
SBA-TETA & $\mathrm{pH}=4$ & 23.9 & {$[47]$} \\
GO-IDA & $\mathrm{pH}=6.5$ & 108.4 & {$[21]$} \\
PEI-WS & $\mathrm{pH}=6$ & 52.2 & {$[48]$} \\
IRC748 chelating resin & $\mathrm{pH}=5$ & 107.39 & {$[36]$} \\
IRC86 cation-exchange resin & $\mathrm{pH}=5$ & 47.21 & {$[49]$} \\
waste wood-based panels derived AC & $\mathrm{pH}=5$ & 25.04 & Present study \\
OAC & $\mathrm{pH}=5$ & 53.99 & Present study \\
IDA-OAC & $\mathrm{pH}=5$ & 83.75 & Present study \\
\hline
\end{tabular}




\subsection{Effect of Contact Time and Adsorption Kinetics}

To assess the adsorption rate and the equilibrium time between adsorbate and copper ions, the result of contact time on the adsorption capacity is displayed in Figure 7. In the beginning, the removal of $\mathrm{Cu}$ (II) rapidly increased for $\mathrm{AC}, \mathrm{OAC}$, and IDA-OAC as the contact time increased. In $60 \mathrm{~min}$, most of the adsorbates were attracted to IDA-OAC (more than $80 \%$ of the adsorption capacity). The reaction became slow until it finally reached equilibrium at almost $120 \mathrm{~min}$ for the three adsorbents, and the adsorption capacity depended on different materials. The fact that adsorbents can uptake copper ions quickly at first might be attributed to a higher driving force and the amount of uncovered active sites on the adsorbents [39]. Subsequently, the adsorption rate slows for the adsorption sites after saturation. Aryee et al. reported that the copper adsorption on modified peanut husk went through two stages and reached equilibrium by three hours [26]. Laconica et al. used triethylenetetramine to modify mesoporous silica particles and removed copper ions in eight hours [47].

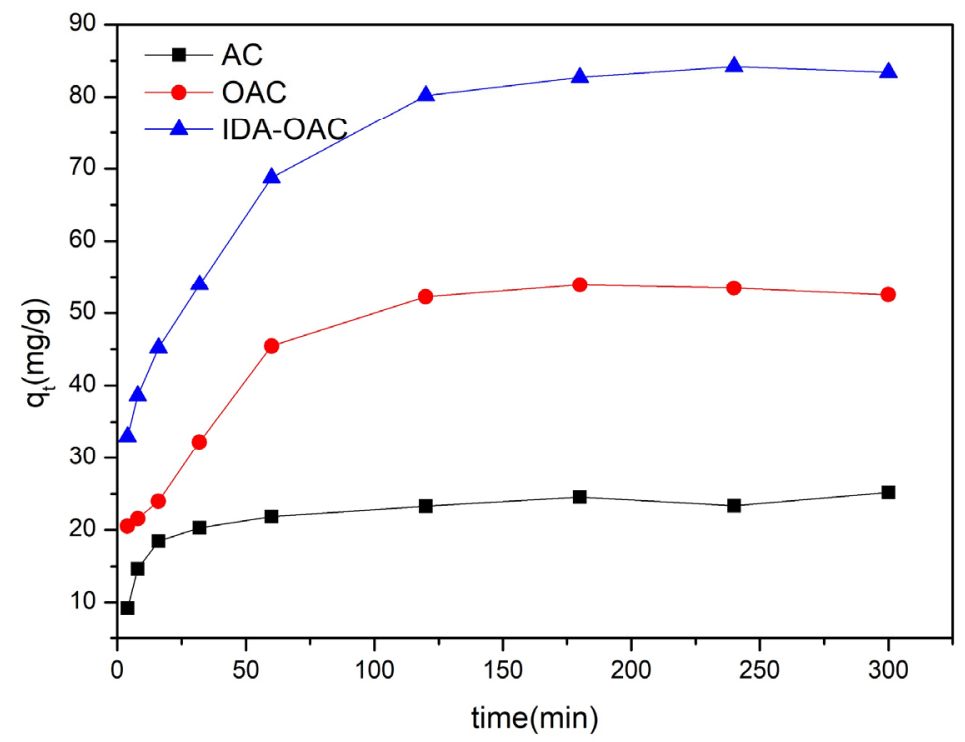

Figure 7. Effect of contact time for the adsorbents on the $\mathrm{Cu}(\mathrm{II})$ sorption.

The experimental data about the effect of contact time were fitted by a pseudo-firstorder kinetic model and pseudo-second-order kinetic model for this study. Two kinds of classical models can examine the controlling mechanism for the adsorption process. The pseudo-first model considers that the adsorbate undergoes sorption by the physical adsorption process. The pseudo-second model is controlled by chemical interaction [50]. Through the kinetic model plots and adsorption parameters for $\mathrm{Cu}(\mathrm{II})$ adsorption presented in Figure 8 and Table 5, it can be determined that the correlations between the pseudosecond model for AC, OAC, and IDA-OAC were greater than 0.99 . The result from Razak et al. also found that the pseudo-second-order kinetic model was better fitted than the pseudo-first-order one by IDA-modified fiber sorption [22]. Neto et al. researched the kinetics model of copper interacted with a chelating group found the correlation factor of pseudo-second-order was 0.986 [51]. The ligand from the oxygen and nitrogen could donate ions for transitional metals. This proved that the primary interaction in the adsorption process was the exchanging or sharing of electrons. 


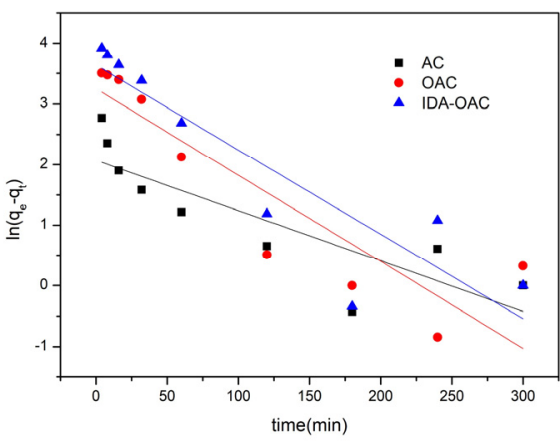

(a)

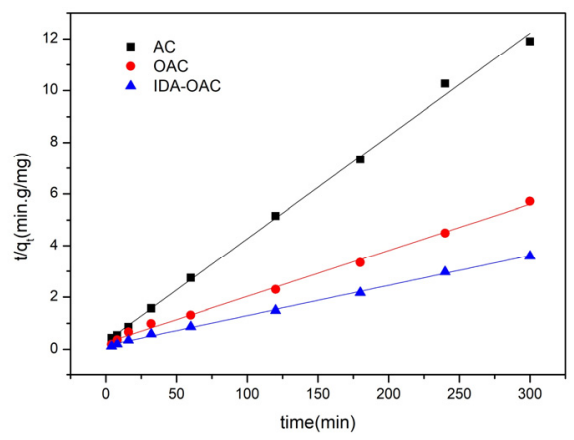

(b)

Figure 8. Linear plots of (a) pseudo-first-order kinetic and (b) pseudo-second-order kinetic models of $\mathrm{AC}, \mathrm{OAC}$, and IDA-OAC adsorption for $\mathrm{Cu}(\mathrm{II})$.

Table 5. The fitting results of pseudo-first order and pseudo-second order kinetic models.

\begin{tabular}{ccccc}
\hline Sample & \multicolumn{2}{c}{ Pseudo-First Order } & \multicolumn{2}{c}{ Pseudo-Second Order } \\
\hline & $\boldsymbol{k}_{\boldsymbol{f}} \mathbf{( \mathbf { 1 } / \mathbf { m i n } )}$ & $\boldsymbol{R}^{\mathbf{2}}$ & $\boldsymbol{K}_{\boldsymbol{s}} \mathbf{( 1 / \mathbf { m i n } )}$ & $\boldsymbol{R}^{\mathbf{2}}$ \\
\hline AC & 0.0083 & 0.6913 & 0.0053 & 0.9976 \\
OAC & 0.0142 & 0.7952 & 0.0012 & 0.9963 \\
IDA-OAC & 0.0139 & 0.8007 & 0.0009 & 0.9981 \\
\hline
\end{tabular}

\subsection{Thermodynamics of Adsorption}

The data from the effect of temperature on the adsorption process were used in the van't Hoff equation for determining the three thermodynamic parameters $\Delta \mathrm{G}^{\circ}, \Delta \mathrm{H}^{\circ}$, and $\Delta S^{\circ}$. The positive sign of $\Delta \mathrm{H}^{\circ}$ from Table 6 indicates that the adsorption process was endothermic for $A C, O A C$, and IDA-OAC. The negative value of $\Delta G^{\circ}$ showed that the reaction process was spontaneous and decreased as the temperature increased [29]. This implies that the higher temperature is suitable for adsorption. Moreover, the $\Delta S^{\circ}$ of the IDA$\mathrm{OAC}$ was larger than $\mathrm{OAC}$ and $\mathrm{AC}$. This phenomenon proved the high random adsorption between the adsorbents and copper ions to obtain more affinity to the adsorbate [30].

Table 6. Thermodynamic parameters for the AC, OAC, and IDA-OAC.

\begin{tabular}{ccccc}
\hline Sample & Temperature (K) & $\boldsymbol{\Delta G}^{\circ} \mathbf{( \mathbf { k J } / \mathbf { m o l } )}$ & $\boldsymbol{\Delta} \mathbf{H}^{\circ} \mathbf{( \mathbf { k J } / \mathbf { m o l } )}$ & $\boldsymbol{\Delta} \mathbf{S}^{\circ} \mathbf{( J / m o l ~ K )}$ \\
\hline \multirow{2}{*}{ AC } & 298 & -11.96 & & \\
& 308 & -12.50 & 4.25 & 54.36 \\
\hline \multirow{2}{*}{ OAC } & 318 & -13.04 & & \\
& 298 & -13.87 & & \\
& 308 & -14.45 & 4.36 & \\
IDA-OAC & 318 & -15.09 & & \\
& 298 & -14.95 & 3.62 & \\
\hline
\end{tabular}

\subsection{Reusability of IDA}

In the reusability experiments, to use the $0.1 \mathrm{M} \mathrm{HCl}, 0.1 \mathrm{M} \mathrm{H}_{2} \mathrm{SO}_{4}$, and $0.1 \mathrm{M} \mathrm{HNO}_{3}$ were conducted in the regeneration of IDA-OAC, respectively. The results revealed $0.1 \mathrm{M}$ $\mathrm{HCl}$ had higher desorption efficiency (96.89\%) than $0.1 \mathrm{M} \mathrm{HNO}_{3}(86.47 \%)$ and $0.1 \mathrm{M} \mathrm{H}_{2} \mathrm{SO}_{4}$ $(82.02 \%)$. Therefore, the $0.1 \mathrm{M} \mathrm{HCl}$ was the eluent for desorption of IDA-OAC. Figure 9 presents the four adsorption-desorption cycles. The adsorption efficiency decline could be because some copper ions were stuck in the adsorbents because the IDA-OAC had high 
porosity [12]. Or perhaps, the $\mathrm{Cu}^{2+}$ occupied the active site and had not been released during the desorbing process [44]. Although the adsorption capacity decreased gradually, it could also maintain high adsorption capacity $(77.56 \mathrm{mg} / \mathrm{g})$ after four cycles, which means IDA-OAC is an economical and efficient adsorbent for water treatment.

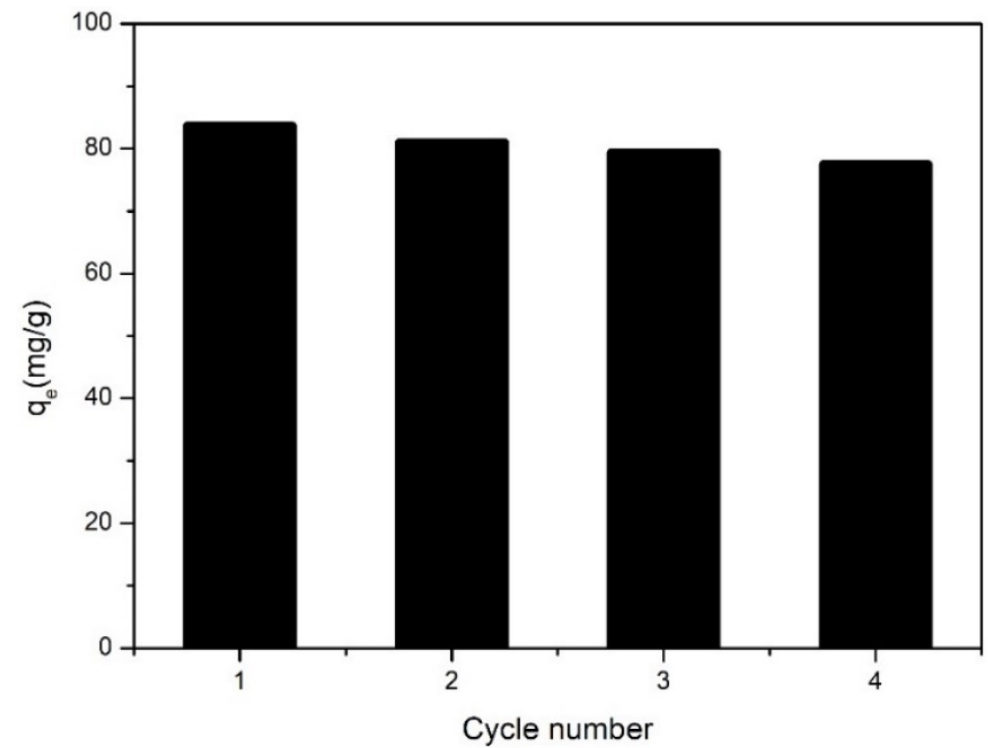

Figure 9. Variation in adsorption of $\mathrm{Cu}(\mathrm{II})$ in cycles of regeneration from IDA-OAC.

\subsection{Column Sorption of $\mathrm{Cu}(\mathrm{II})$}

To enhance the application of the AC, OAC, and IDA-OAC in practice, Figure 10 illustrates the different adsorption abilities for the adsorbents in the column scale. The breakthrough curve can provide better awareness of the adsorbents characteristic to control the effluent from industry in practical applications. For AC, the breakthrough points $\left(C_{t} / C_{i}=0.05\right)$ and the exhaustion points $\left(C_{t} / C_{i}=0.95\right)$ are seen at $19 \mathrm{BV}$ and $32 \mathrm{BV}$, respectively. Relatively, the OAC and IDA-OAC had higher bed volumes for breakthrough points (37 BV and $52 \mathrm{BV}$ ) and exhaustion points (66 BV and $77 \mathrm{BV})$. This means oxidized, activated carbon and grafted functional groups can also enhance the performance of sorption copper ions for adsorbents in the column scale. Further, the total removal efficiency for IDA-OAC was $83.54 \%$, clearly higher than OAC $(74.63 \%)$ and AC $(73.53 \%)$. This result can ensure that the adsorbate is removed more effectively from the aqueous solution by IDA-OAC.

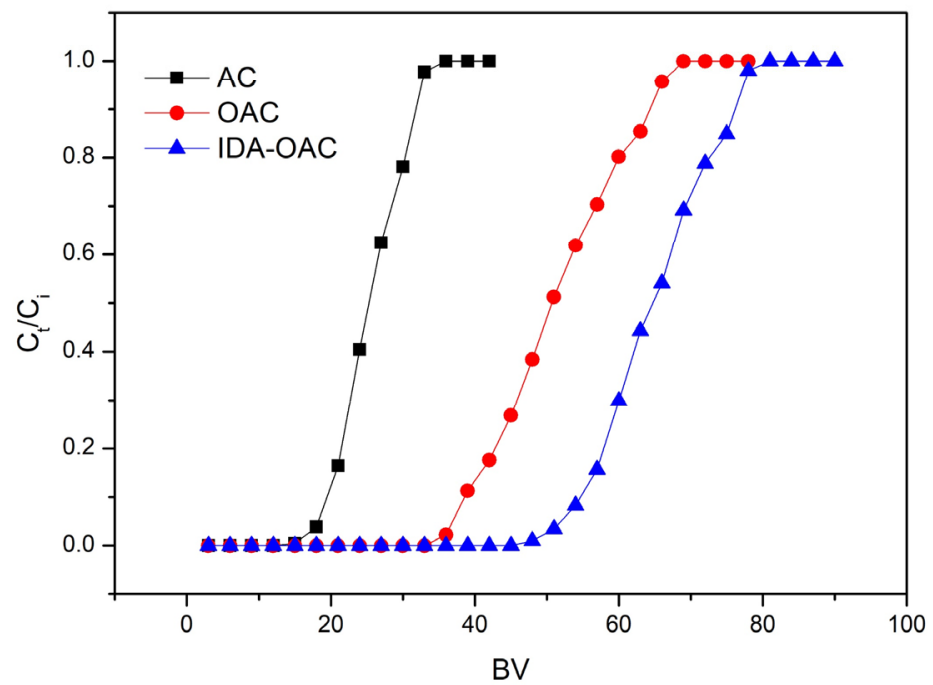

Figure 10. Column sorption of copper for AC, OAC, and IDA-OAC at initial concentration $50 \mathrm{mg} / \mathrm{L}$. 


\section{Conclusions}

In this study, the nitric acid and iminodiacetic acid functional group successfully modified the activated carbon derived from waste wood-based panels. With the introduction of the oxygen-containing group on the $\mathrm{AC}$, the adsorbents exhibited a high affinity for copper ions, especially the IDA-OAC. In the batch experiment, the adsorption data from $\mathrm{AC}, \mathrm{OAC}$, and IDA-OAC were well-explained by Langmuir isotherm and pseudo-second models. The adsorption capacity data $q_{m}(\mathrm{mg} / \mathrm{g})$ for IDA-OAC $(83.75 \mathrm{mg} / \mathrm{g})$ from the Langmuir isotherm model were higher than AC $(25.04 \mathrm{mg} / \mathrm{g})$ and OAC $(53.99 \mathrm{mg} / \mathrm{g})$. Through the oxidized and grafted AC, adsorption capacity increased by about $220 \%$ and $340 \%$ from the equilibrium adsorption result. Because of the high affinity between IDA and metal ions, the IDA-OAC could efficiently remove copper ions from the low-concentration solution and retain high adsorption capacity in high ion strength. The result of the column experiment demonstrated that grafting AC made the breakthrough point occur later (from $19 \mathrm{BV}$ to $52 \mathrm{BV}$ ). The test of the IDA-OAC regeneration proved the good reusability and high stability for the sorption of $\mathrm{Cu}^{2+}$. This reveals that the $\mathrm{AC}$ and the modified carbon material have great characterization and are more cost-effective as highly potential adsorbents for water treatment.

Author Contributions: Conceptualization, Y.-C.C.; Data curation, Y.-C.C.; Formal analysis, Y.-C.C.; Investigation, Y.-C.C.; Methodology, W.-S.C., Y.-C.C. and C.-H.L.; Supervision, W.-S.C. and C.-H.L.; Visualization, Y.-C.C.; Writing—original draft, Y.-C.C.; Writing—review and editing, C.-H.L. All authors have read and agreed to the published version of the manuscript.

Funding: This research received no external funding.

Acknowledgments: We wish to acknowledge the support of the Laboratory of Resources Circulation (LRC) at National Cheng Kung University.

Conflicts of Interest: The authors declare no conflict of interest.

\section{References}

1. Awad, F.S.; AbouZeid, K.M.; El-Maaty, W.M.A.; El-Wakil, A.M.; El-Shall, M.S. Efficient Removal of Heavy Metals from Polluted Water with High Selectivity for Mercury(II) by 2-Imino-4-thiobiuret-Partially Reduced Graphene Oxide (IT-PRGO). ACS Appl. Mater. Interfaces 2017, 9, 34230-34242. [CrossRef] [PubMed]

2. Schwarzenbach, R.P.; Escher, B.I.; Fenner, K.; Hofstetter, T.B.; Johnson, C.A.; von Gunten, U.; Wehrli, B. The Challenge of Micropollutants in Aquatic Systems. Science 2006, 313, 1072-1077. [CrossRef] [PubMed]

3. Haroon, H.; Shah, J.A.; Khan, M.S.; Alam, T.; Khan, R.; Asad, S.A.; Ali, M.A.; Farooq, G.; Iqbal, M.; Bilal, M. Activated carbon from a specific plant precursor biomass for hazardous $\mathrm{Cr}(\mathrm{VI})$ adsorption and recovery studies in batch and column reactors: Isotherm and kinetic modeling. J. Water Process. Eng. 2020, 38, 101577. [CrossRef]

4. Mulungulungu, G.A.; Mao, T.; Han, K. Efficient removal of high-concentration copper ions from wastewater via 2D g-C3N4 photocatalytic membrane filtration. Colloids Surf. A Physicochem. Eng. Asp. 2021, 623, 126714. [CrossRef]

5. Demiral, H.; Güngör, C. Adsorption of copper(II) from aqueous solutions on activated carbon prepared from grape bagasse. J. Clean. Prod. 2016, 124, 103-113. [CrossRef]

6. Virolainen, S.; Wesselborg, T.; Kaukinen, A.; Sainio, T. Removal of iron, aluminium, manganese and copper from leach solutions of lithium-ion battery waste using ion exchange. Hydrometallurgy 2021, 202, 105602. [CrossRef]

7. Ho, C.-C.; Yu, J.-S.; Yang, S.-W.; Ya, V.; Le, H.A.; Cheng, L.-P.; Choo, K.-H.; Li, C.-W. Use of packed scrap iron anodes for continuous electrochemical $\mathrm{Cr}(\mathrm{VI})$ reduction process in electroplating wastewater treatment. J. Water Process. Eng. 2021, 42, 102191. [CrossRef]

8. Tsai, T.-H.; Chou, H.-W.; Wu, Y.-F. Removal of nickel from chemical plating waste solution through precipitation and production of microsized nickel hydroxide particles. Sep. Purif. Technol. 2020, 251, 117315. [CrossRef]

9. Yen, F.-C.; You, S.-J.; Chang, T.-C. Performance of electrodialysis reversal and reverse osmosis for reclaiming wastewater from high-tech industrial parks in Taiwan: A pilot-scale study. J. Environ. Manag. 2017, 187, 393-400. [CrossRef] [PubMed]

10. Jin, J.; Li, S.; Peng, X.; Liu, W.; Zhang, C.; Yang, Y.; Han, L.; Du, Z.; Sun, K.; Wang, X. $\mathrm{HNO}_{3}$ modified biochars for uranium (VI) removal from aqueous solution. Bioresour. Technol. 2018, 256, 247-253. [CrossRef]

11. Imran, M.; Khan, Z.U.H.; Iqbal, M.M.; Iqbal, J.; Shah, N.S.; Munawar, S.; Ali, S.; Murtaza, B.; Naeem, M.A.; Rizwan, M. Effect of biochar modified with magnetite nanoparticles and $\mathrm{HNO}_{3}$ for efficient removal of $\mathrm{Cr}(\mathrm{VI})$ from contaminated water: $\mathrm{A}$ batch and column scale study. Environ. Pollut. 2020, 261, 114231. [CrossRef] [PubMed]

12. Queiroz, L.S.; de Souza, L.K.; Thomaz, K.T.C.; Lima, E.T.L.; Filho, G.N.D.R.; Nascimento, L.D.; Pires, L.H.D.O.; Faial, K.D.C.F.; da Costa, C.E. Activated carbon obtained from amazonian biomass tailings (acai seed): Modification, characterization, and use for removal of metal ions from water. J. Environ. Manag. 2020, 270, 110868. [CrossRef] 
13. El-Wakil, A.M.; Abou El-Maaty, W.M.; Awad, F.S. Removal of Lead from Aqueous Solution on Activated Carbon and Modified Activated Carbon Prepared from Dried Water Hyacinth Plant. J. Anal. Bioanal. Technol. 2014, 5, 187. [CrossRef]

14. Zuo, X.; Liu, Z.; Chen, M. Effect of $\mathrm{H}_{2} \mathrm{O}_{2}$ concentrations on copper removal using the modified hydrothermal biochar. Bioresour. Technol. 2016, 207, 262-267. [CrossRef] [PubMed]

15. Aryee, A.A.; Mpatani, F.M.; Zhang, X.; Kani, A.N.; Dovi, E.; Han, R.; Li, Z.; Qu, L. Iron (III) and iminodiacetic acid functionalized magnetic peanut husk for the removal of phosphate from solution: Characterization, kinetic and equilibrium studies. J. Clean. Prod. 2020, 268, 122191. [CrossRef]

16. Karthikeyan, T.; Rajgopal, S.; Miranda, L.R. Chromium(VI) adsorption from aqueous solution by Hevea Brasilinesis sawdust activated carbon. J. Hazard. Mater. 2005, 124, 192-199. [CrossRef] [PubMed]

17. Yorgun, S.; Yildız, D. Preparation and characterization of activated carbons from Paulownia wood by chemical activation with $\mathrm{H}_{3} \mathrm{PO}_{4}$. J. Taiwan Inst. Chem. Eng. 2015, 53, 122-131. [CrossRef]

18. Fierro, V.; Muñiz, G.; Basta, A.; El-Saied, H.; Celzard, A. Rice straw as precursor of activated carbons: Activation with orthophosphoric acid. J. Hazard. Mater. 2010, 181, 27-34. [CrossRef]

19. Xu, D.; Yang, L.; Zhao, M.; Zhang, J.; Syed-Hassan, S.S.A.; Sun, H.; Hu, X.; Zhang, H.; Zhang, S. Conversion and transformation of N species during pyrolysis of wood-based panels: A review. Environ. Pollut. 2020, 270, 116120. [CrossRef]

20. Wu, Y.; Fan, Y.; Zhang, M.; Ming, Z.; Yang, S.; Arkin, A.; Fang, P. Functionalized agricultural biomass as a low-cost adsorbent: Utilization of rice straw incorporated with amine groups for the adsorption of $\mathrm{Cr}(\mathrm{VI})$ and $\mathrm{Ni}(\mathrm{II})$ from single and binary systems. Biochem. Eng. J. 2016, 105, 27-35. [CrossRef]

21. Pytlakowska, K.; Matussek, M.; Hachuła, B.; Pilch, M.; Kornaus, K.; Zubko, M.; Pisarski, W.A. Graphene oxide covalently modified with 2,2'-iminodiacetic acid for preconcentration of $\mathrm{Cr}$ (III), $\mathrm{Cu}$ (II), $\mathrm{Zn}$ (II) and $\mathrm{Pb}$ (II) from water samples prior to their determination by energy dispersive X-ray fluorescence spectrometry. Spectrochim. Acta Part B At. Spectrosc. 2018, 147, 79-86. [CrossRef]

22. Razak, M.R.; Yusof, N.A.; Haron, M.J.; Ibrahim, N.; Mohammad, F.; Kamaruzaman, S.; Al-Lohedan, H.A. Iminodiacetic acid modified kenaf fiber for waste water treatment. Int. J. Biol. Macromol. 2018, 112, 754-760. [CrossRef] [PubMed]

23. Junior, A.B.B.; Vicente, A.D.A.; Espinosa, D.C.R.; Tenório, J.A.S. Recovery of metals by ion exchange process using chelating resin and sodium dithionite. J. Mater. Res. Technol. 2019, 8, 4464-4469. [CrossRef]

24. Yunus, Z.M.; Al-Gheethi, A.; Othman, N.; Hamdan, R.; Ruslan, N.N. Removal of heavy metals from mining effluents in tile and electroplating industries using honeydew peel activated carbon: A microstructure and techno-economic analysis. J. Clean. Prod. 2019, 251, 119738. [CrossRef]

25. Güzel, F.; Sayğıll, H.; Sayğılı, G.A.; Koyuncu, F.; Yılmaz, C. Optimal oxidation with nitric acid of biochar derived from pyrolysis of weeds and its application in removal of hazardous dye methylene blue from aqueous solution. J. Clean. Prod. 2017, 144, 260-265. [CrossRef]

26. Aryee, A.A.; Mpatani, F.M.; Du, Y.; Kani, A.N.; Dovi, E.; Han, R.; Li, Z.; Qu, L. $\mathrm{Fe}_{3} \mathrm{O}_{4}$ and iminodiacetic acid modified peanut husk as a novel adsorbent for the uptake of $\mathrm{Cu}$ (II) and $\mathrm{Pb}$ (II) in aqueous solution: Characterization, equilibrium and kinetic study. Environ. Pollut. 2020, 268, 115729. [CrossRef] [PubMed]

27. Fu, Y.; Wu, J.; Zhou, H.; Jin, G. Removal of nickel(II) from aqueous solutions using iminodiacetic acid functionalized polyglycidyl methacrylate grafted-carbon fibers. Chin. J. Chem. Eng. 2015, 23, 919-923. [CrossRef]

28. Li, B.; Guo, J.-Z.; Liu, J.-L.; Fang, L.; Lv, J.-Q.; Lv, K. Removal of aqueous-phase lead ions by dithiocarbamate-modified hydrochar. Sci. Total. Environ. 2020, 714, 136897. [CrossRef]

29. Khadhri, N.; Saad, M.E.K.; ben Mosbah, M.; Moussaoui, Y. Batch and continuous column adsorption of indigo carmine onto activated carbon derived from date palm petiole. J. Environ. Chem. Eng. 2018, 7, 102775. [CrossRef]

30. Kyzas, G.; Deliyanni, E.A.; Matis, K.A. Activated carbons produced by pyrolysis of waste potato peels: Cobalt ions removal by adsorption. Colloids Surf. A Physicochem. Eng. Asp. 2016, 490, 74-83. [CrossRef]

31. Tounsadi, H.; Khalidi, A.; Machrouhi, A.; Farnane, M.; Elmoubarki, R.; Elhalil, A.; Sadiq, M.; Barka, N. Highly efficient activated carbon from Glebionis coronaria L. biomass: Optimization of preparation conditions and heavy metals removal using experimental design approach. J. Environ. Chem. Eng. 2016, 4, 4549-4564. [CrossRef]

32. Zhang, Y.; He, Z.B.; Xue, L.; Chu, D.M.; Mu, J. Influence of a urea-formaldehyde resin adhesive on pyrolysis characteristics and volatiles emission of poplar particleboard. RSC Adv. 2016, 6, 12850-12861. [CrossRef]

33. Kędzierska-Matysek, M.; Matwijczuk, A.; Florek, M.; Barłowska, J.; Wolanciuk, A.; Matwijczuk, A.; Chruściel, E.; Walkowiak, R.; Karcz, D.; Gładyszewska, B. Application of FTIR spectroscopy for analysis of the quality of honey. BIO Web Conf. 2018, 10, 02008. [CrossRef]

34. Giridhar, N.; Pandey, K.; Prasad, B.; Bisht, S.; Vagdevi, H. Dimensional stabilization of wood by chemical modification using isopropenyl acetate. Maderas. Ciencia y Tecnol. 2017, 19, 15-20. [CrossRef]

35. Ramírez-Herrera, C.; Cruz-Cruz, I.; Jiménez-Cedeño, I.; Martínez-Romero, O.; Elías-Zúñiga, A. Influence of the Epoxy Resin Process Parameters on the Mechanical Properties of Produced Bidirectional $\left[ \pm 45^{\circ}\right]$ Carbon/Epoxy Woven Composites. Polymers 2021, 13, 1273. [CrossRef] [PubMed]

36. Ling, P.; Liu, F.; Li, L.; Jing, X.; Yin, B.; Chen, K.; Li, A. Adsorption of divalent heavy metal ions onto IDA-chelating resins: Simulation of physicochemical structures and elucidation of interaction mechanisms. Talanta 2010, 81, 424-432. [CrossRef] 
37. Guo, J.-Z.; Li, B.; Liu, L.; Lv, K. Removal of methylene blue from aqueous solutions by chemically modified bamboo. Chemosphere 2014, 111, 225-231. [CrossRef]

38. Yan, Y.; Ma, X.; Cao, W.; Zhang, X.; Zhou, J.; Liu, Q.; Qian, G. Identifying the reducing capacity of biomass derived hydrochar with different post-treatment methods. Sci. Total. Environ. 2018, 643, 486-495. [CrossRef]

39. Wally, S.M.; El-Wakil, A.M.; El-Maaty, W.M.A.; Awad, F.S. Efficient removal of $\mathrm{Pb}(\mathrm{II})$ and $\mathrm{Hg}$ (II) ions from aqueous solution by amine and thiol modified activated carbon. J. Saudi Chem. Soc. 2021, 25, 101296. [CrossRef]

40. Hidalgo, J.J.T.; Rosas, J.; Palomo, J.; Romero, M.J.V.; Rodriguez-Mirasol, J.; Cordero, T. Functionalization of activated carbons by $\mathrm{HNO}_{3}$ treatment: Influence of phosphorus surface groups. Carbon 2016, 101, 409-419. [CrossRef]

41. Oginni, O.; Singh, K.; Oporto, G.; Dawson-Andoh, B.; McDonald, L.; Sabolsky, E. Effect of one-step and two-step $\mathrm{H}_{3} \mathrm{PO}_{4}$ activation on activated carbon characteristics. Bioresour. Technol. Rep. 2019, 8, 100307. [CrossRef]

42. Xie, R.; Jin, Y.; Chen, Y.; Jiang, W. The importance of surface functional groups in the adsorption of copper onto walnut shell derived activated carbon. Water Sci. Technol. 2017, 76, 3022-3034. [CrossRef]

43. Liu, Y.; Fu, R.; Sun, Y.; Zhou, X.; Baig, S.A.; Xu, X. Multifunctional nanocomposites $\mathrm{Fe}_{3} \mathrm{O}_{4} @ \mathrm{SiO}_{2}-\mathrm{EDTA}$ for Pb(II) and Cu(II) removal from aqueous solutions. Appl. Surf. Sci. 2016, 369, 267-276. [CrossRef]

44. Perez, I.D.; Anes, I.A.; Junior, A.B.B.; Espinosa, D.C.R. Comparative study of selective copper recovery techniques from nickel laterite leach waste towards a competitive sustainable extractive process. Clean. Eng. Technol. 2020, 1, 100031. [CrossRef]

45. Imran, M.; Anwar, K.; Akram, M.; Shah, G.M.; Ahmad, I.; Shah, N.S.; Khan, Z.U.H.; Rashid, M.I.; Akhtar, M.N.; Ahmad, S.; et al. Biosorption of $\mathrm{Pb}(\mathrm{II})$ from contaminated water onto Moringa oleifera biomass: Kinetics and equilibrium studies. Int. J. Phytoremediat. 2019, 21, 777-789. [CrossRef] [PubMed]

46. Sun, H.; Ji, Z.; He, Y.; Wang, L.; Zhan, J.; Chen, L.; Zhao, Y. Preparation of PAMAM modified PVDF membrane and its adsorption performance for copper ions. Environ. Res. 2021, 204, 111943. [CrossRef] [PubMed]

47. Lachowicz, J.I.; Delpiano, G.R.; Zanda, D.; Piludu, M.; Sanjust, E.; Monduzzi, M.; Salis, A. Adsorption of $\mathrm{Cu}^{2+}$ and $\mathrm{Zn}^{2+}$ on SBA-15 mesoporous silica functionalized with triethylenetetramine chelating agent. J. Environ. Chem. Eng. 2019, 7, 103205. [CrossRef]

48. Dong, J.; Du, Y.; Duyu, R.; Shang, Y.; Zhang, S.; Han, R. Adsorption of copper ion from solution by polyethylenimine modified wheat straw. Bioresour. Technol. Rep. 2019, 6, 96-102. [CrossRef]

49. Chandramohan, K.; Marimuthu, S. Adsorptive Removal of Copper from Aqueous Solution by Amberlite Cation-Exchange Resin-Equilibrium and Kinetic Studies. In Proceedings of the 2011 International Conference on Biology, Environment and Chemistry, Dubai, United Arab Emirates, 28-30 December 2011; pp. 28-30.

50. Agarwal, A.; Upadhyay, U.; Sreedhar, I.; Singh, S.; Patel, C.M. A review on valorization of biomass in heavy metal removal from wastewater. J. Water Process Eng. 2020, 38, 101602. [CrossRef]

51. Neto, I.F.; Sousa, C.A.; Brito, M.S.; Futuro, A.M.; Soares, H.M. A simple and nearly-closed cycle process for recycling copper with high purity from end life printed circuit boards. Sep. Purif. Technol. 2016, 164, 19-27. [CrossRef] 